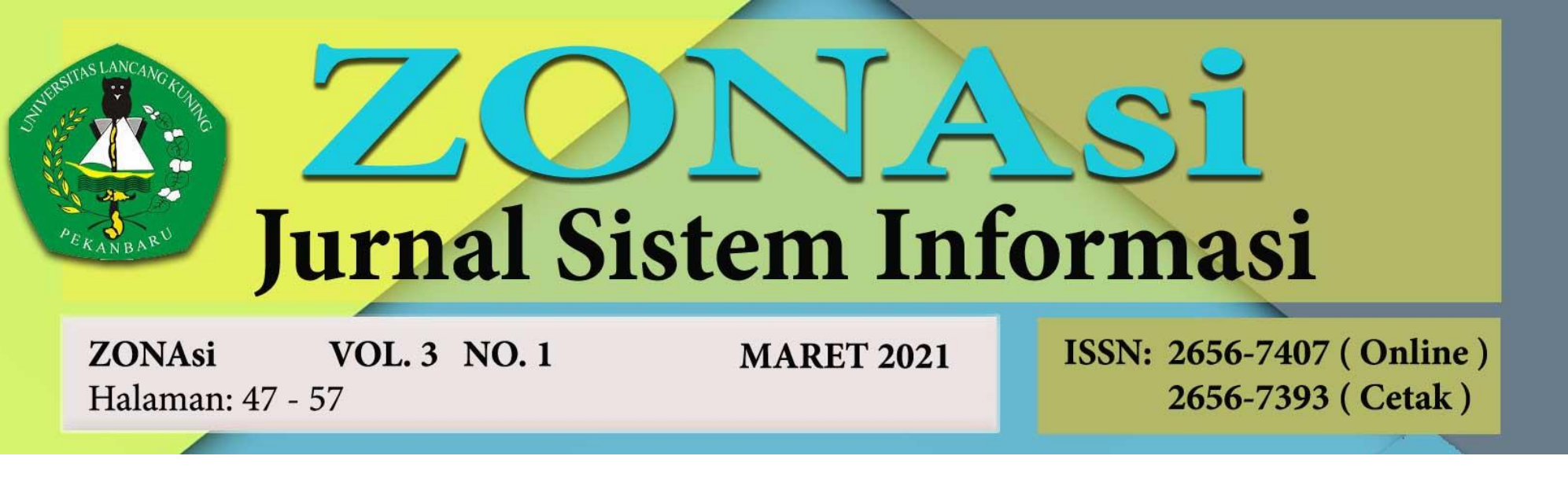

\title{
APLIKASI MANAJEMEN KEUANGAN FAKULTAS ILMU KOMPUTER UNIVERSITAS LANCANG KUNING
}

\author{
Susi Handayani ${ }^{1}$, Edi Kurniawan ${ }^{2}$ \\ ${ }^{1,2}$ Program Studi Teknik Informatika Fakultas Ilmu Komputer Universitas Lancang Kuning \\ Address, Telp/fax \\ 1,2(J1. Yos Sudarso KM.8 Rumbai, Pekanbaru, Riau, telp. 0811753 2015) \\ e-mail : ${ }^{1}$ susi@unilak.ac.id, ${ }^{2}$ awan.edi96@gmail.com
}

\begin{abstract}
Abstrak
Penelitian ini dilakukan untuk membuat sebuah aplikasi manajemen keuangan pada Fakultas Ilmu Komputer Universitas Lancang Kuning berbasis web, karena pada saat ini Fakultas Ilmu Komputer Universitas Lancang Kuning belum mempunyai aplikasi manajemen berbasis web, sehingga untuk mengelola data keuangan yaitu uang masuk dan uang keluar masih menggunakan Microsoft Excel sehingga datanya tidak bisa diakses. Penelitian ini bertujuan untuk merancang dan membangun sebuah aplikasi manajemen keuangan pada Fakultas Ilmu Komputer Universitas Lancang Kuning. Dalam perancangan aplikasi ini menggunakan pemodelan UML (Unified Modelling Language) dan metode yang digunakan dalam penelitian ini menggunakan metode waterfall. Pembuatan program menggunakan bahasa program PHP, MySQL sebagai database dan menggunakan framework CodeIgniter. Hasil dari penelitian ini adalah sebuah aplikasi manajemen keuangan Fakultas Ilmu Komputer Universitas Lancang Kuning.
\end{abstract}

Kata Kunci : Aplikasi, Waterfall, $P H P, M y S Q L$, CodeIgniter.

\section{Abstract}

This research doing to make finances management application of Computer Science Faculty of Lancang Kuning University basis on web, because in this time the Faculty of Computer Science of Lancang Kuning University has no management application with web basis, that's why, to manage input and output's finance still use Microsoft Excel. This research purposed to help finances management's division to manage finance data there are input and output finance, perhaps that this application can do more than before application. The method that used in this research is waterfall method. The making programe used PHP programe language, MySQL as database and used framework CodeIgniter to build finances management aplication of Computer Science Faculty of Lancang Kuning University.

Keyword : Application, Waterfall, PHP, MySQL, CodeIgniter. 


\section{PENDAHULUAN}

Teknologi dan informasi yang berkembang pada saat ini sangat pesat dan beragam, sesuai dengan kebutuhan dan kesesuaian teknologi dengan kondisi yang membutuhkan di setiap lembaga perguruan tinggi maupun perusahaan.

Perkembangan teknologi informasi dan komunikasi, membuat manusia dapat menciptakan sebuah aplikasi yang membantu mempermudah pekerjaan manusia yang sulit apalagi jika dilakukan secara manual. Oleh karena itu, sebuah aplikasi saat ini merupakan kebutuhan yang wajib bagi beberapa suatu lembaga pemerintahan serta perguruan tinggi negeri ataupun perguruan tinggi swasta, bahkan juga bisa memenuhi kebutuhan bagi beberapa individu.

Saat ini, Fakultas Ilmu Komputer Universitas Lancang Kuning belum mempunyai aplikasi manajemen keuangan berbasis web. Akan tetapi, dalam mengelola data keuangan baik uang masuk maupun uang keluar sudah menggunakan komputer. Namun, penggunaan komputer tersebut masih belum maxsimal karena penggelolaan data keuangan masih dilakukan menggunakan Aplikasi yang memiliki fungsionalitas untuk pengunaan umum sehingga data dan informasinya tidak bisa di akses.

Apikasi manajemen keuangan merupakan aplikasi yang digunakan untuk melakukan transaksi keuangan, membuat laporan keuangan baik uang masuk maupun uang keluar yang dilakukan oleh operator dan admin. Dengan aplikasi ini pembuatan laporan bisa dilakukan secara cepat tanpa harus memindahkan data transaksi ke laporan secara manual, sehingga dalam pembuatan laporan keuangan lebih cepat dan efisien dalam penggunaan waktu dan tenaga, karena jika jumlah data transaksi keuangan baik uang masuk maupun uang keluar yang terjadi sangat banyak banyak, maka akan membutuhkan waktu dan tenaga yang banyak untuk membuatan laporan tersebut. tentunya apabila masalah-masalah yang terjadi tidak segera diperbaiki maka tidak akan mampu mengikuti perkembangan dan kebutuhan teknologi di masa akan datang.

\section{METODE PENELITIAN}

Adapun teknik pengumpulan data yang dilakukan adalah sebagai berikut :

\subsection{Studi Lapangan}

\section{a. Observasi}

Dalam obsevasi ini yang dilakukan adalah dengan melihat langsung kondisi tempat penelitian yaitu di Fakultas Ilmu Komputer Universitas Lancang Kuning.

b. Wawancara

Wawanca dilakukan dengan bagian keuangan yaitu Wakil Dekan II di Fakultas Ilmu Komputer Universitas Lancang Kuning.

\subsection{Studi Kepustakaan}

Dilakukan dengan cara membaca buku atau jurnal yang berhubungan dengan judul penelitian

Metode yang digunakan dalam penelitian ini menggunakan metode waterfall, yaitu: 


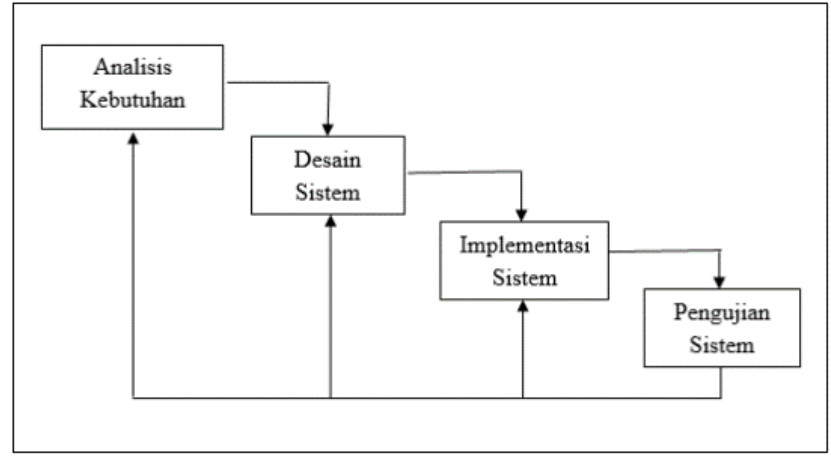

Gambar 1. Metode Waterfall

1. Analisis Kebutuhan

Pada proses analisis kebutuhan, adapun yang dilakukan peneliti adalah:

a. Identifikasi Masalah

Identifikasi masalah adalah tahap yang dilakukan untuk mengetahui permasalahan apa yang sedang terjadi pada bagian keuangan Fakutas Ilmu Komputer Universitas Lancang Kuning.

b. Analisa Sistem

Analisa sistem merupakan proses penjabaran dari suatu sistem yang ada kedalam bagian komponennya agar kita bisa mengidentifikasi masalah yang ada pada sistem tersebut dengan tujuan bisa memberikan solusi dari permasalahan tersebut.

c. Kebutuhan Data

Pada proses ini peneliti mencari dan mengumpulkan data yang dibutuhkan dalam desain aplikasi manajemen keuangan Fakutas Ilmu Komputer Universitas Lancang Kuning.

\section{Desain Sistem}

Pada tahap ini peneliti mendesain kerangka kerja atau cara kerja sistem, dalam hal mendesain aplikasi manajemen keuangan Fakultas Ilmu Komputer Universitas Lancang Kuning yang akan dibangun dengan menggunakan Unified Modelling Language (UML).

\section{Implementasi Sistem}

Pada tahap ini, adapun yang dilakukan peneliti adalah sebagai berikut:

a. Desain Interface

Desain Interface merupakan desain antarmuka pengguna terhadap sistem, yang dibuat untuk memudahkan pengguna dalam berinteraksi terhadap sistem.

b. Penulisan Program

Pada tahap ini, programmer dapat menuliskan program yang akan dibangun kedalam software programming yang digunakan seperti Sublime Text 3, Xampp 3.2.2, framework CodeIgniter dan lain-lain, sehingga menghasilkan sistem yang telah di desain atau dirancang sebelumnya.

c. Keamanan Sistem Komputer

Keamanan sistem komputer harus sesuai dengan standar keamanan komputer, agar data dapat dilindungi dari orang yang tidak berhak menggunakannya, sehingga dapat mencegah penyisipan dan penghapusan data. 


\section{Pengujian Sistem}

Pengujian ini dilakukan untuk mengetahui kelemahan dan kesalahan sebuah sistem yang telah dibuat sehingga dapat dikembangkan lebih lanjut untuk menjadi sebuah sistem dan aplikasi yang layak digunakan.

Pada tahap ini peneliti menggunakan pengujian Black box. Black box merupakan teknik pengujian yang digunakan untuk menguji fungsional terhadap sistem baik itu fungsi sistem maupun terhadap tombol-tombol dari sitem tersebut.

\section{HASIL DAN PEMBAHASAN}

\subsection{Perancangan Sistem}

Pada tahapan ini dilakukan upaya membangun sistem dan mengimplementasikan sistem yang baru dengan memanfaatkan teknologi terbaru dengan fasilitas yang tersedia. Sistem yang dirancang ini, diharapkan memberi solusi dan membantu bagian keuangan dalam mengelola data keuangan baik uang masuk maupun uang keluar pada Fakultas Ilmu Komputer Universitas Lancang Kuning.

Dalam sistem ini, metode perancangannya menggunakan UML (Unified Modelling Language). Berikut adalah diagram-diagram yang digunakan dalam perancangan aplikasi ini :

\section{Use case Diagram}

Usecase diagram menggambarkan sebuah interaksi antara Actor dengan sistem.

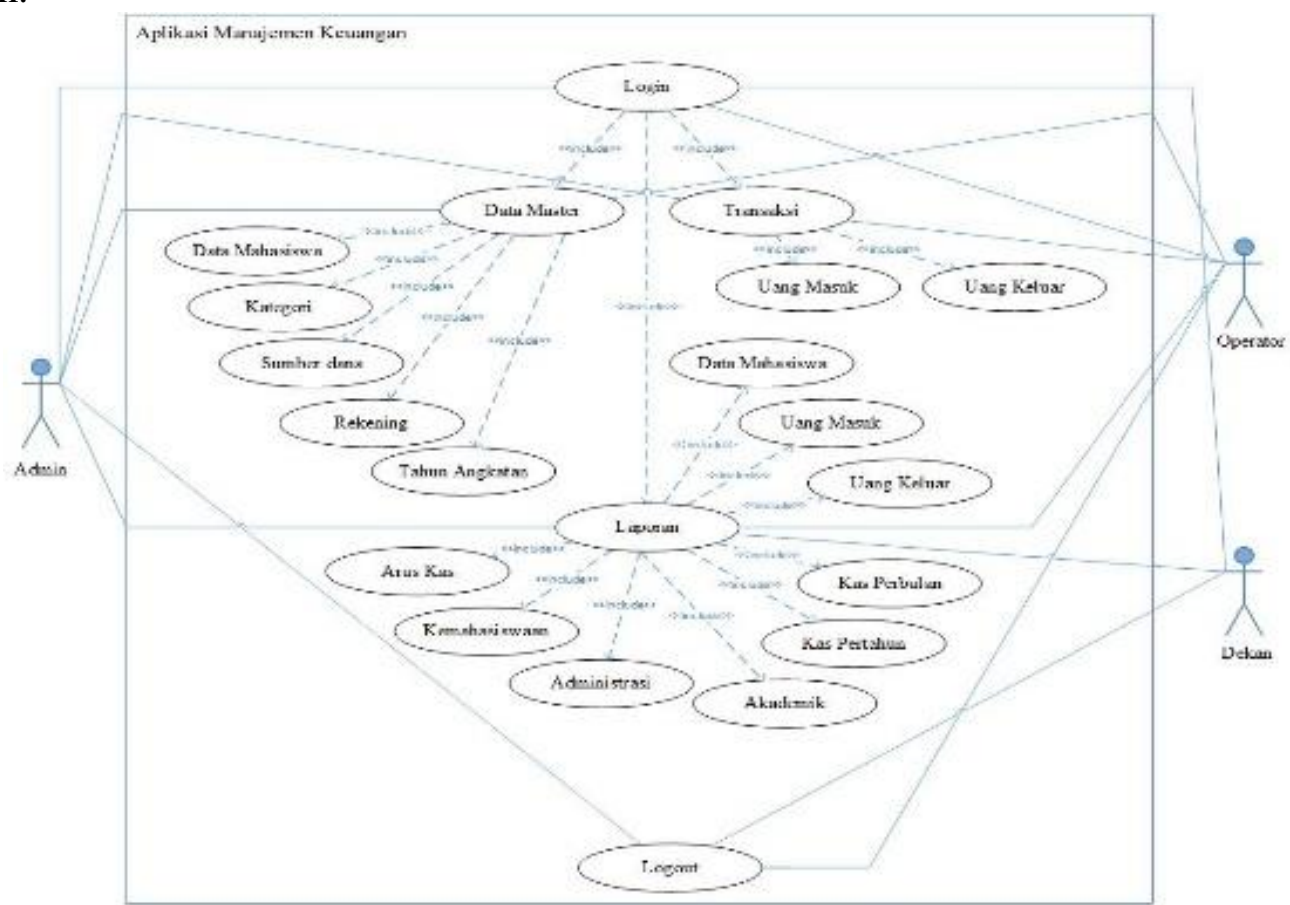

Gambar 2. Use Case Diagram

\section{Class Diagram}

Class diagram menggambarkan struktur sistem dari segi pendefinisian kelas-kelas yang akan dibuat untuk membangun sistem. 


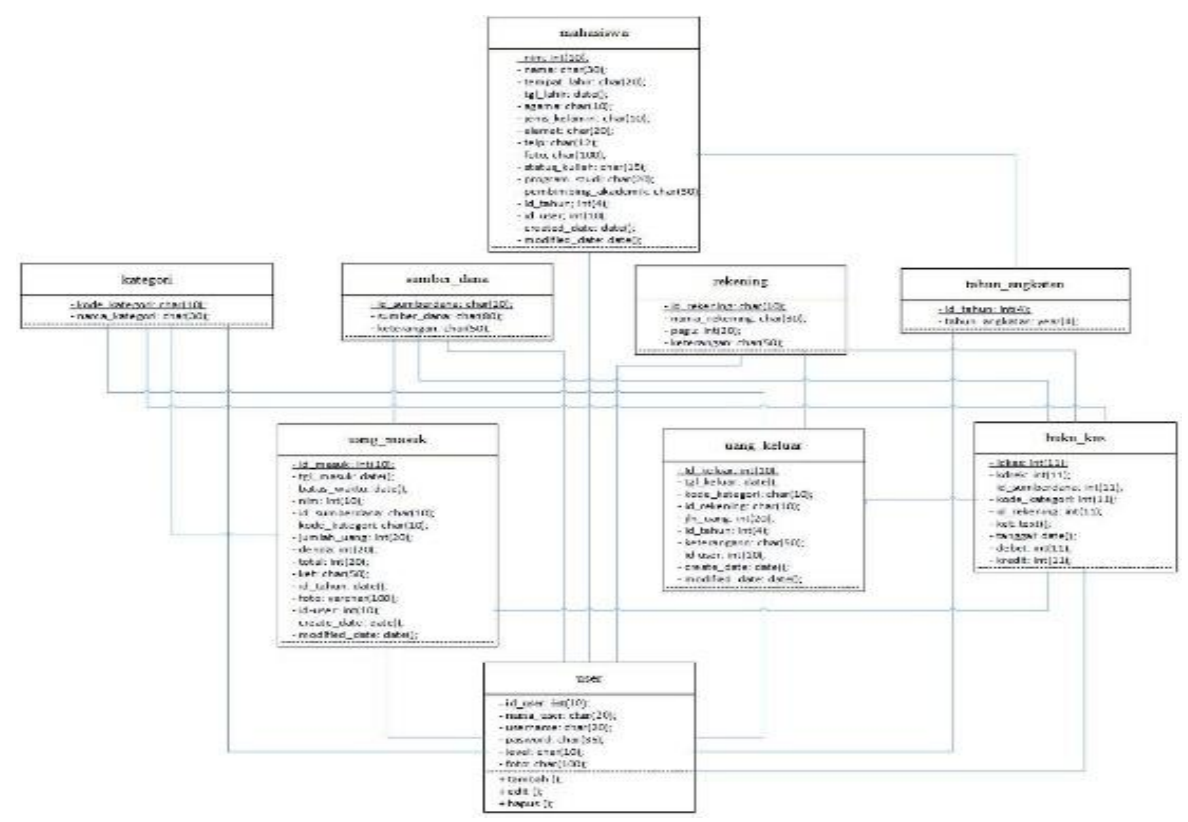

Gambar 3. Class diagram

\section{Sequence Diagram}

Sequence diagram meggambarkan kalaborasi antar sejumlah objek, yang digunakan untuk menunjukkan rangkaian pesan yang dikirim antar objek dan interaksi antar objek.

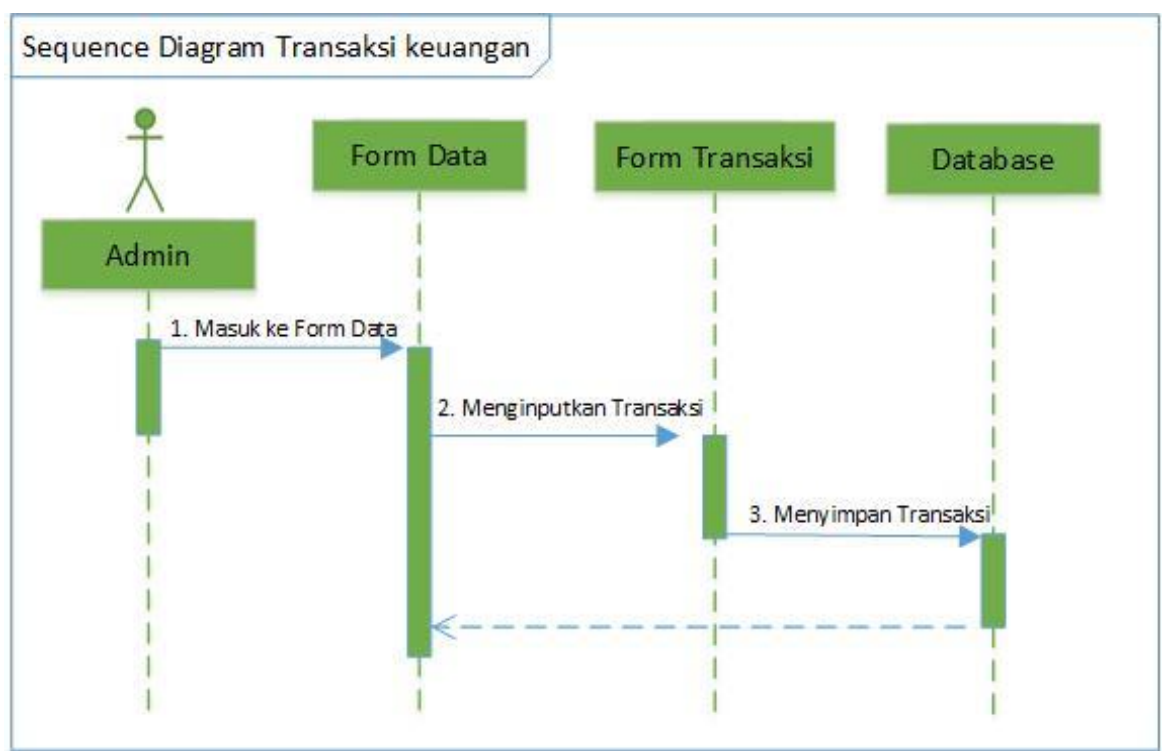

Gambar 4. Sequence diagram

\section{Activity Diagram}

Activity Diagram menggambarkan aliran kerja atau aktifitas dari sebuah sistem. 


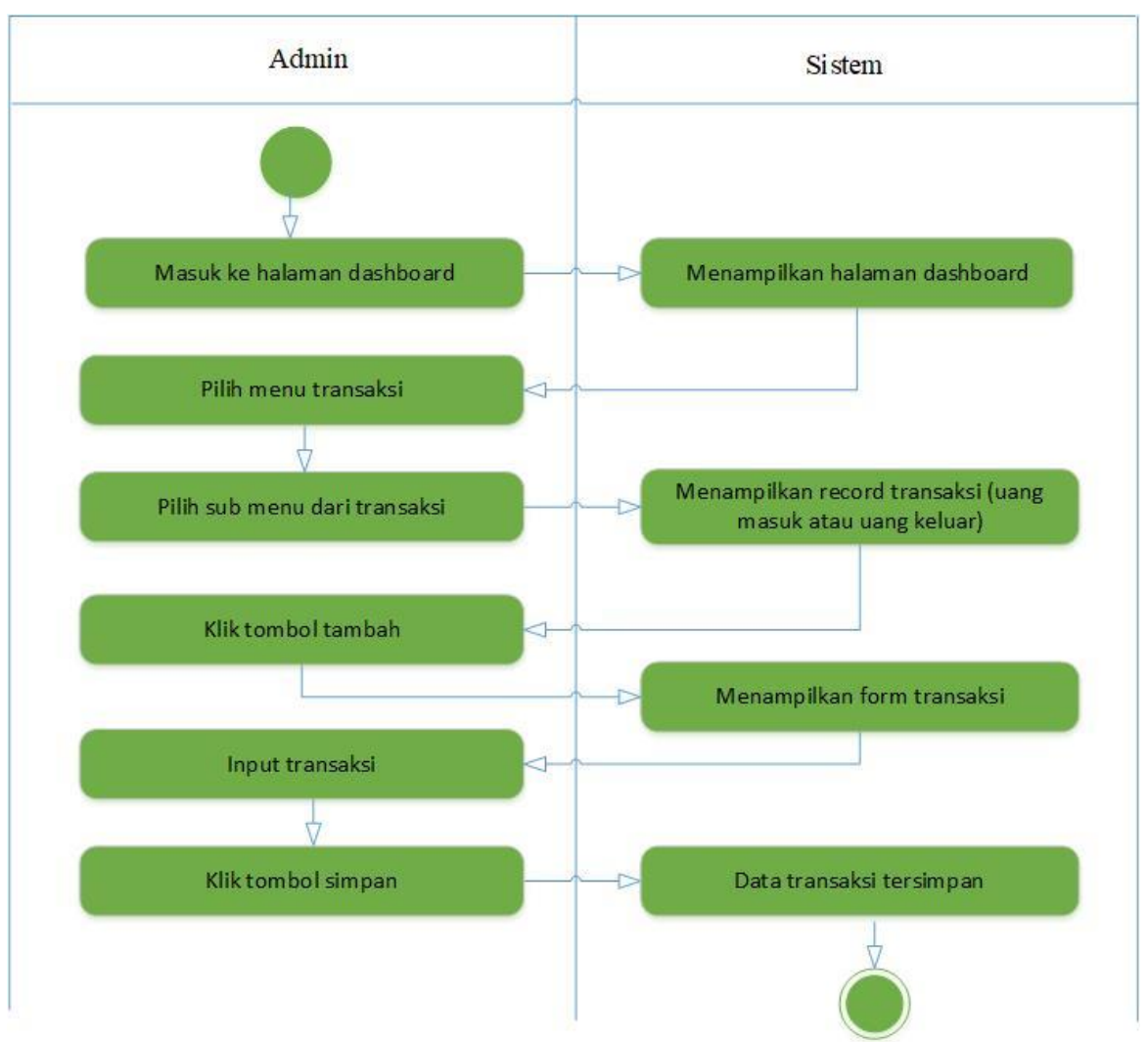

Gambar 5. Activity diagram

\subsection{Desain File Database}

Dalam perancangan sistem dibutuhkan file untuk memudahkan penyimpanan dan pengambilan informasi penggolah data. Adapun desain file yang ada didalam database tersebut sebagai berikut:

3.2.1. Desain tabel uang masuk

Nama database : dbkeuangan.sql

Nama tabel : uang_masuk

Prymary key : id_masuk 
Tabel .1 Uang Masuk

\begin{tabular}{|c|c|c|c|c|}
\hline No & Filed Name & Type & Size & Descripsion \\
\hline 1 & id masuk & int & 10 & Id uang masuk \\
\hline 2 & tgl_masuk & date & & Tangggal uang masuk \\
\hline 3 & batas_waktu & date & & Batas pembayaran \\
\hline 4 & $\operatorname{nim}$ & int & 10 & No Induk Mahasiswa \\
\hline 5 & id_sumberdana & varchar & 10 & Id sumberdana \\
\hline 6 & kode_kategori & varchar & 10 & Kode kategori \\
\hline 7 & jumlah_uang & int & 20 & Jumlah uang masuk \\
\hline 8 & denda & int & 20 & Denda keterlambatan \\
\hline 9 & total & int & 20 & Total uang masuk \\
\hline 10 & ket & text & & Keterangan uang masuk \\
\hline 11 & id_tahun & int & 4 & Id Tahun \\
\hline 12 & foto & varchar & 100 & Foto bukti pembayaran \\
\hline 13 & id_user & int & 10 & Id user \\
\hline 14 & created_date & date & & Tanggal dibuat \\
\hline 15 & modified_date & date & & Tanggal di edit \\
\hline
\end{tabular}

3.2.1. Desain tabel uang keluar

Nama database: dbkeuangan.sql

Nama tabel : uang_keluar

Prymary key : id_keluar

Tabel 2. Uang Keluar

\begin{tabular}{|l|l|l|l|l|}
\hline No & \multicolumn{1}{|c|}{ Filed Name } & Type & Size & \multicolumn{1}{c|}{ Descripsion } \\
\hline 1 & id keluar & int & 10 & Id laporan keuangan \\
\hline 2 & tgl_keluar & date & & Tanggal uang keluar \\
\hline 3 & kode_kategori & varchar & 10 & Kode kategori \\
\hline 4 & id_rekening & varchar & 10 & Id rekening \\
\hline 5 & jlh_uang & int & 20 & Jumlah uang keluar \\
\hline 6 & id_tahun & int & 4 & Id tahun \\
\hline 6 & keterangann & text & & Keterangan uang keluar \\
\hline 7 & id_user & int & 10 & Id user \\
\hline 8 & created_date & date & & Tanggal di buat \\
\hline 9 & modified_date & date & & Tanggal di edit \\
\hline
\end{tabular}

\subsection{Tampilan Implementasi}

Implementasi Aplikasi Manajemen Keuangan Fakultas Ilmu Komputer Universitas Lancang Kuning.

3.3.1. Hasil implementasi tampilan login 


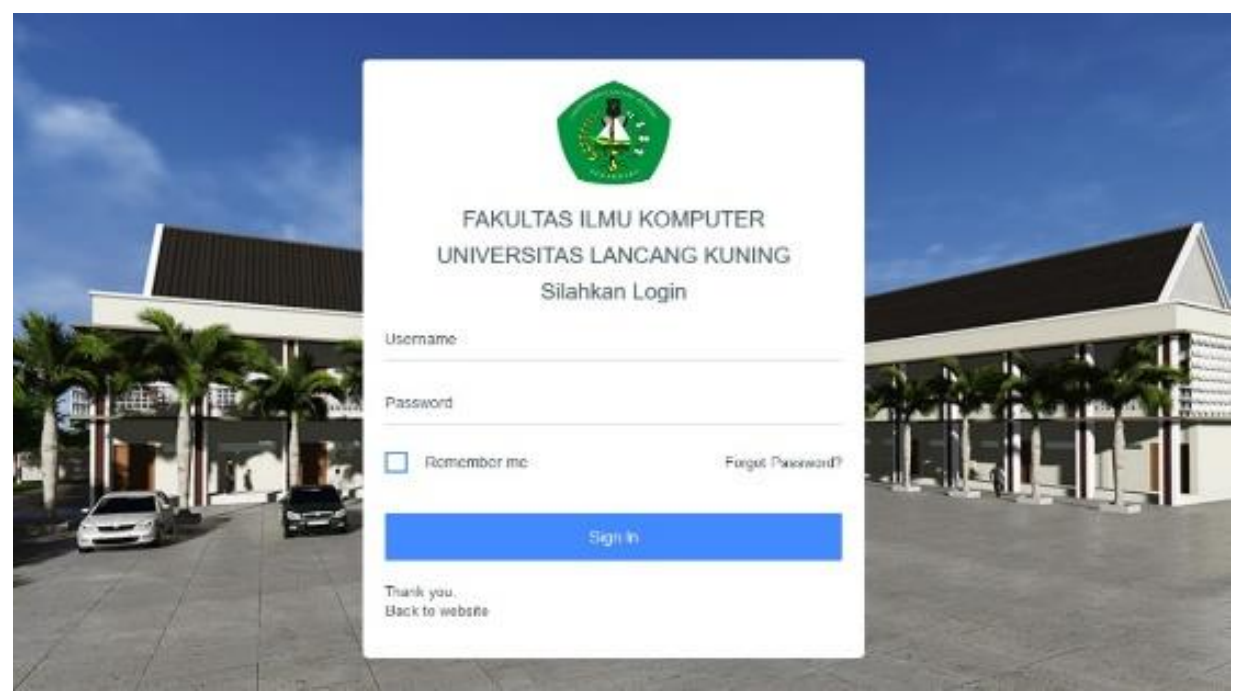

Gambar 6. Halaman implementasi tampilan login

3.3.2. Hasil implementasi tampilan halaman utama admin

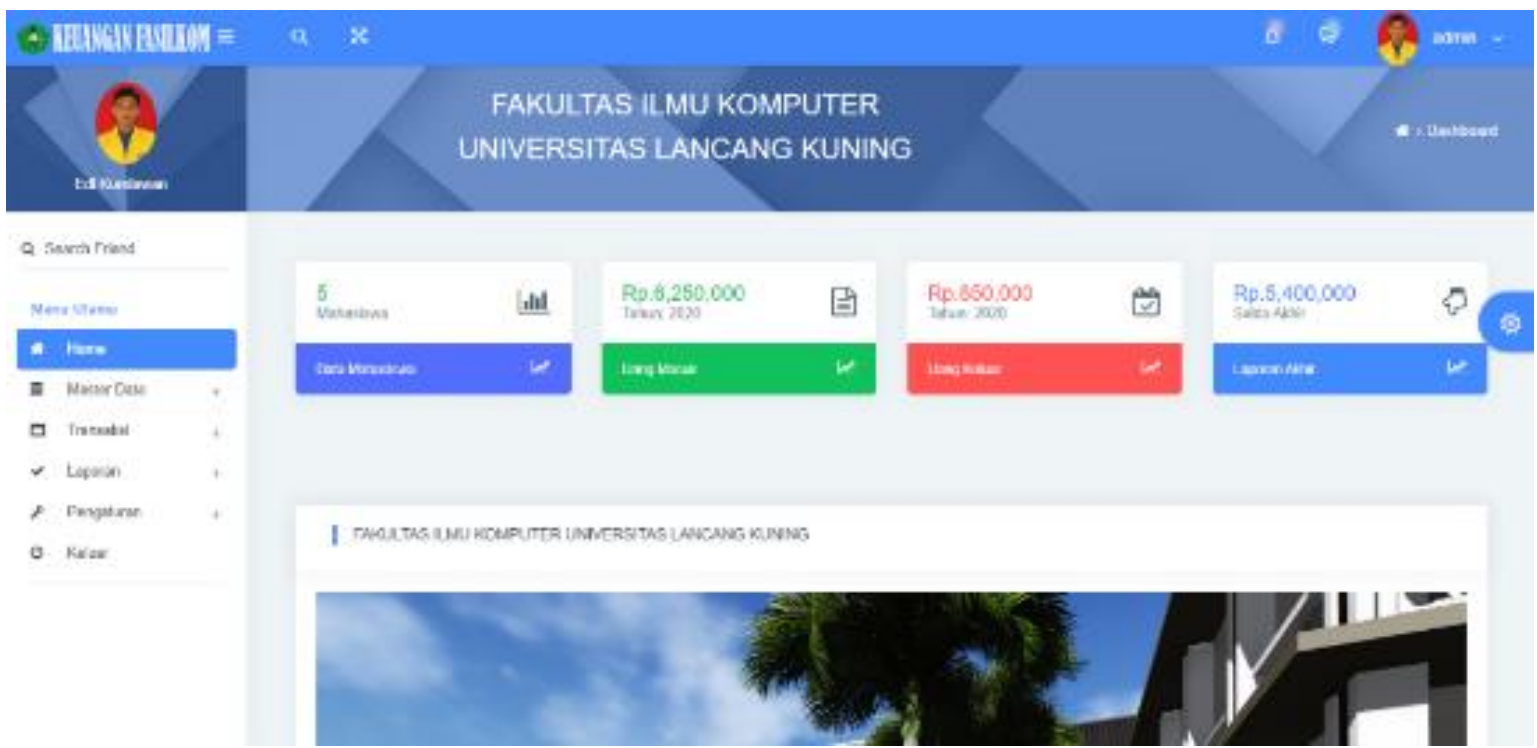

Gambar 7. Halaman Implementasi tampilan halaman utama admin 
3.3.3. Hasil implementasi tampilan halaman input data uang masuk

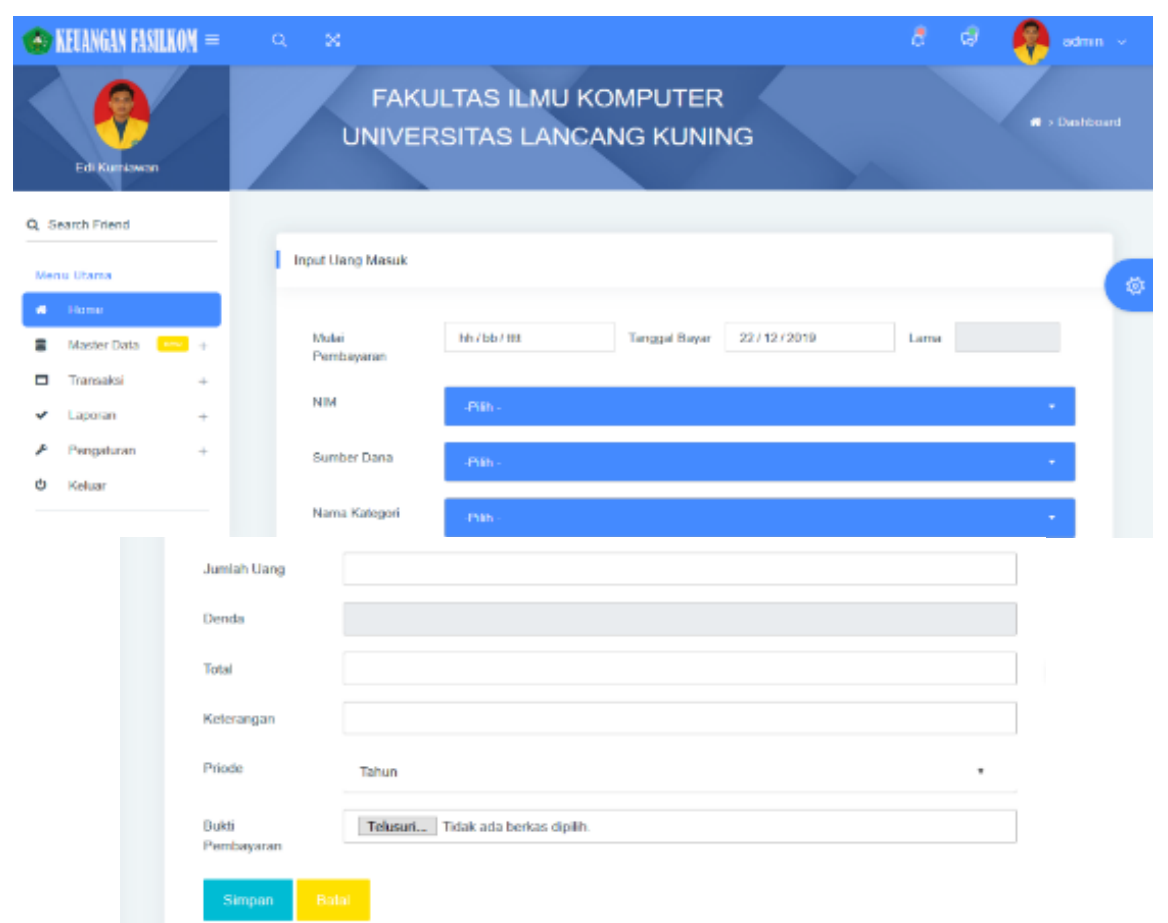

Gambar 8. Halaman Implementasi tampilan halaman input data uang masuk

3.3.4. Hasil implementasi tampilan halaman input data uang keluar

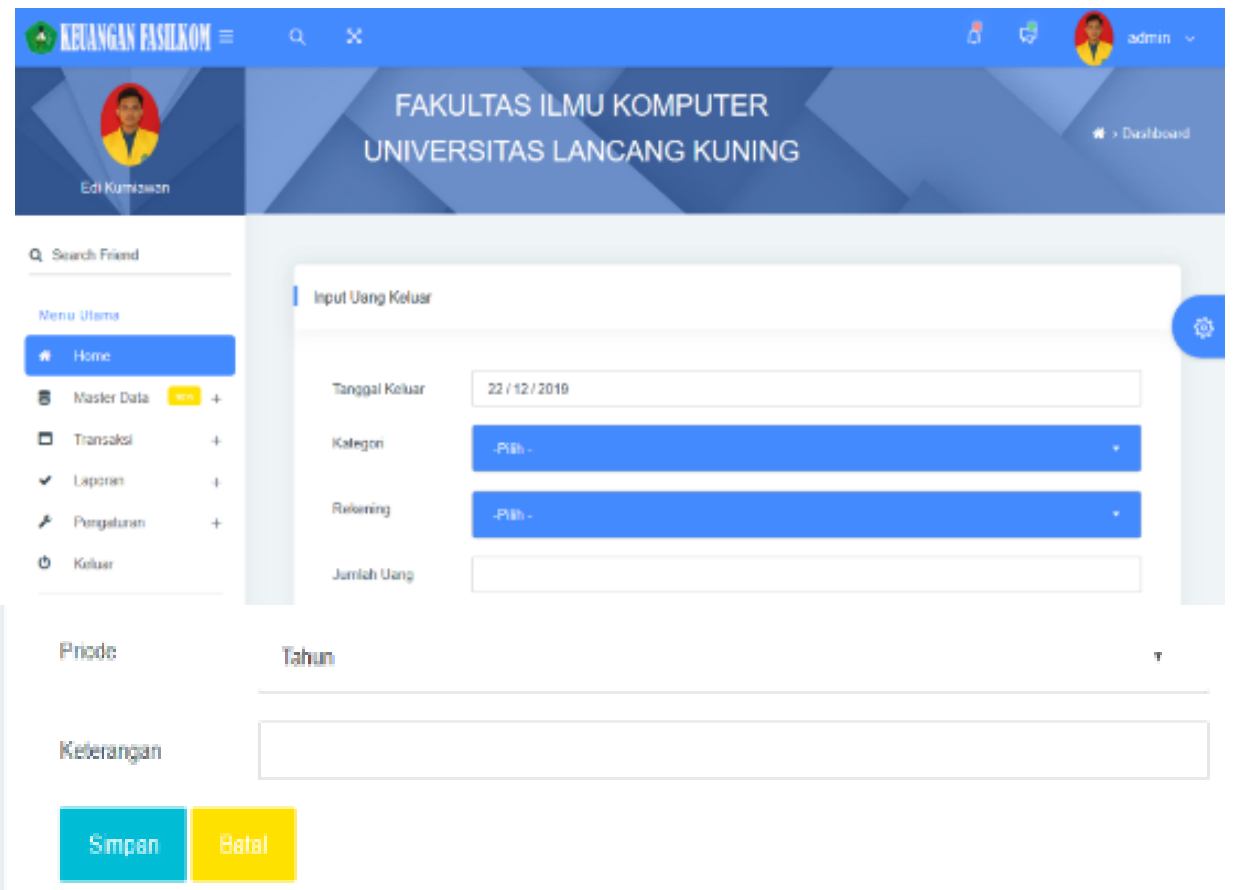

Gambar 9. Halaman Implementasi tampilan halaman input data uang keluar 
3.3.5. Hasil implementasi laporan arus kas (cash flow)

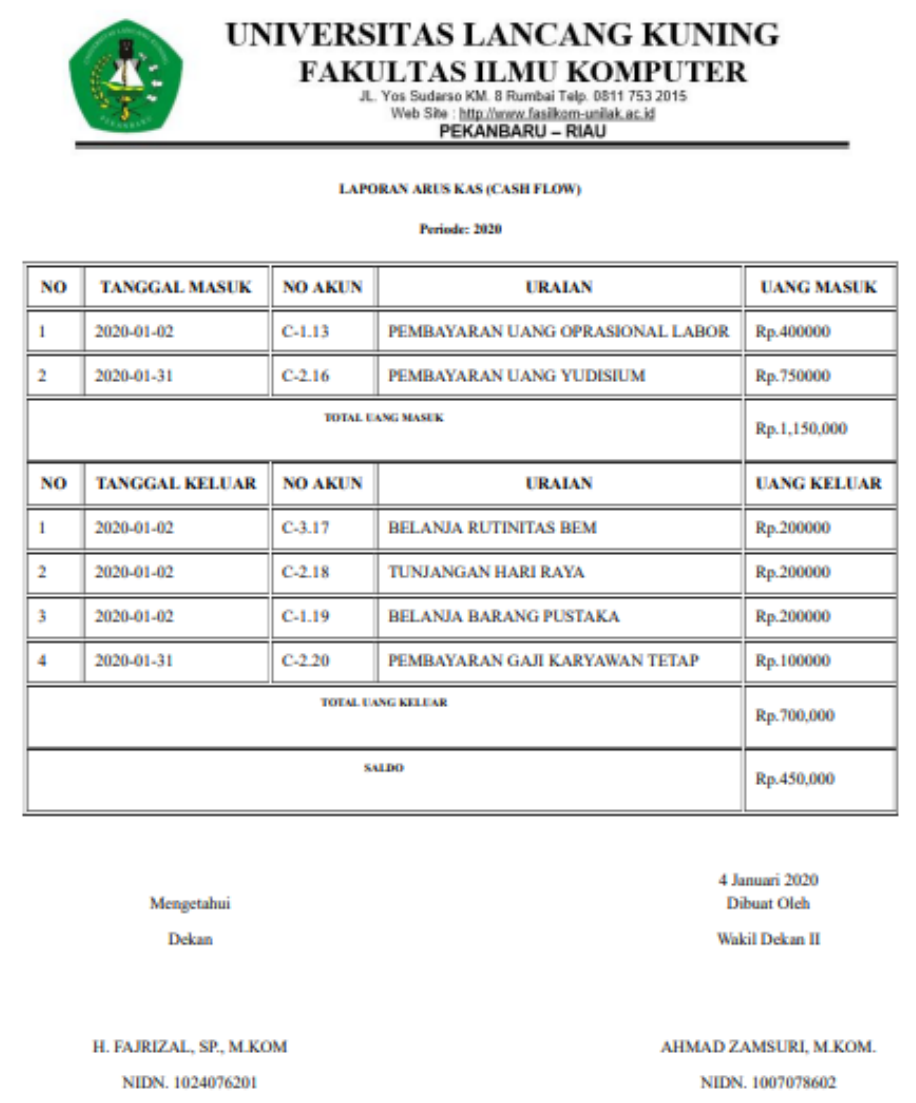

Gambar 10. Halaman Implementasi laporan arus kas (cash flow)

\section{KESIMPULAN}

Dari hasil pengumpulan data dan perancangan aplikasi manajemen keuangan Fakultas Ilmu Komputer Universitas Lancang Kuning, maka dapat disimpulkan bahwa Perancangan aplikasi manajemen keuangan Fakultas Ilmu Komputer Universitas Lancang Kuning menggunakan pemodelan UML (Unified Modelling Language). Dan Aplikasi manajemen keuangan Fakultas Ilmu Komputer Universitas Lancang Kuning digunakan untuk mengelola data keuangan yaitu uang masuk dan uang keluar yang dibangun berbasis web sehingga datanya bisa di akses.

\section{DAFTAR PUSTAKA}

[1] Diah Puspitasari. 2013. "Sistem Informasi Manajemen perpustakaan berbasis web." Jurnal Pilar Nusa Mandiri.

[2] Fahmi, Khairul, Agus Tri Haryono, Indah Fitri Astuti, and Dedy Cahyadi. 2018. "Perancangan Dan Implementasi Aplikasi Perpustakaan Berbasis Multitenant." Informatika Mulawarman : Jurnal Ilmiah Ilmu Komputer.

[3] Hadisuryanto, Ari, Rosadi Kardian, and Kata Kunci. 2016. "Sistem Pakar Untuk Mengukur Tingkat Stres Pada Mahasiswa Tingkat Akhir Dengan Metode Forward Chaining Berbasis Web"

[4] Hendini, Ade. 2016. "Pemodelan UML Sistem Informasi Monitoring 
Penjualan Dan Stok Barang.” Jurnal Khatulistia Informatika.

[5] Nugroho, Arie, and Muhammad Zuhdi Sasongko. 2017. "Informasi Manajemen Pembelajaran Berorientasi Objek." Informasi Manajemen Pembelajaran Berorientasi Objek.

[6] Pahlevi, Omar, Astriana Mulyani, and Miftahul Khoir. 2018. "Sistem Informasi Inventori Barang Menggunakan Metode Object Oriented Di Pt . Livaza Teknologi Indonesia Jakarta"

[7] Pasi, Novlentina, Abdul Kadir, Fakultas Hukum, and Universitas Medan Area. 2017. "Jurnal Administrasi Publik Implementasi Sistem Informasi Manajemen Daerah Keuangan Berbasis Akrual Pada Pemerintah Kebupaten Dairi Implementation of Regional Management Information System Accrual Based to Dairi District Government Sistem Informasi Manajem"

[8] Purnama, Bambang Eka. 2013. "Microsoft Word - 45 Sistem Informasi Pengelolaan Keuangan Sekolah Pada Sekolah Menengah Kejuruan SMK Pgri 1 Pacitan"

[9] Sanjaya, I Gede Agus. n.d. “ Pengembangan Sistem Informasi Manajemen CV. Intra Media Bali"

[10] Sri Rahayu, Universitas Negeri. 2015. "Sistem Informasi Manajemen Keuangan Pada LPBB Bintang Solusi Mandiri"

[11] Suharsana, I Ketut, I G P Wirarama, Wedashwara Wirawan, Ni Luh, and Ayu Kartika. n.d. "Implementasi Model View Controller Dengan Framework Codeigniter Pada E-Commerce Penjualan Kerajinan Bali"

[12] Sumarlin, Tantik, and Ari Susanti. n.d. "Perancangan Sistem Informasi Manajemen Keuangan Untuk Pengendalian Simpan Pinjam Dan Laporan Keuangan Di Koperasi Semarang"

[13] Tantony Hardiwinata, Putu Wira Buana dan Ni Kadek Ayu Wirdiani. 2015. "Perancangan Sistem Informasi Manajemen Rumah Sakit Modul Akutansi dan Keuangan"

[14] Yulianton, Heribertus, Felix Andreas Sutanto, and Sri Mulyani. 2014. "Rancang Bangun Sistem Informasi Keuangan Berbasis Area Untuk Pengusaha Kecil (Studi Kasus Batik Wijayanti Semarang)” Jurnal Teknologi Inofrmasi dinamik.

[15] Yusran, B, and Ririn Rahmadani Nurdin. 2016. Yusran B., Ririn Rahmadani Nurdin."Analisis Dan Perancangan Sistem Informasi Manajemen Keuangan Rumah Sakit Berbasis Web"

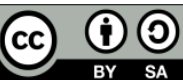
is licensed under a Creative Commons Attribution International (CC BY-SA 4.0) 